\title{
Outer organic layer and internal repair mechanism protects pteropod Limacina helicina from ocean acidification
}

\author{
Victoria L Peck $^{1}$, Geraint A Tarling ${ }^{1}$, Clara Manno ${ }^{1}$, Elizabeth M Harper ${ }^{2}$, Eithne \\ Tynan'. $^{3}$. \\ 1. British Antarctic Survey, High Cross, Madingley Rd, Cambridge, CB5 8NP, UK \\ 2. Department of Earth Sciences, University of Cambridge, Downing Street, Cambridge, \\ CB2 3EQ, UK \\ 3. Ocean and Earth Science, National Oceanography Centre Southampton, University of \\ Southampton Waterfront Campus, European Way, Southampton SO14 3ZH, UK
}

Scarred shells of polar pteropod Limacina helicina collected from the Greenland Sea in June 2012 reveal a history of damage, most likely failed predation, in earlier life stages. Evidence of shell fracture and subsequent re-growth is commonly observed in specimens recovered from the sub-Arctic and further afield. However, at one site within sea-ice on the Greenland shelf, shells that had been subject to mechanical damage were also found to exhibit considerable dissolution. It was evident that shell dissolution was localised to areas where the organic, periostracal sheet that covers the outer shell had been damaged at some earlier stage during the animal's life. Where the periostracum remained intact, the shell appeared pristine with no sign of dissolution. Specimens which appeared to be pristine following collection were incubated for four days. Scarring of shells that received periostracal damage during collection only became evident in specimens that were incubated in waters undersaturated with respect to aragonite, $\Omega_{\mathrm{Ar}} \leq 1$. While the waters from which the damaged specimens were collected at the Greenland Sea sea-ice margin were not $\Omega_{\mathrm{Ar}} \leq 1$, the water column did exhibit the lowest $\Omega A r$ values observed in the Greenland and Barents Seas, and was likely to have approached $\Omega_{\operatorname{Ar}} \leq 1$ during the winter months. We demonstrate that $L$. helicina shells are only susceptible to dissolution where both the periostracum has been breached and the aragonite beneath the breach is exposed to waters of $\Omega_{\mathrm{Ar}} \leq 1$. Exposure of multiple layers of aragonite in areas of deep dissolution indicate that, as with many molluscs, L. helicina is able to patch up dissolution damage to the shell by secreting additional aragonite 
32 internally and maintain their shell. We conclude that, unless breached, the

33 periostracum provides an effective shield for pteropod shells against dissolution in waters $\Omega_{\mathrm{Ar}} \leq 1$, and when dissolution does occur the animal has an effective means of self-repair. We suggest that future studies of pteropod shell condition are undertaken on specimens from which the periostracum has not been removed in preparation.

Key words

Limacina helicina

Ocean acidification

41

Periostracum

42

Greenland

Sea ice

44

Pteropod

45 


\section{INTRODUCTION}

Since the start of the Industrial Revolution, about $48 \%$ of the anthropogenic $\mathrm{CO}_{2}$ emitted to the atmosphere has been sequestered into the world's oceans (Sabine et al., 2004). This excess $\mathrm{CO}_{2}$ is dissolved into the surface ocean and reacts with seawater, causing $\mathrm{pH}$ and dissolved carbonate ion concentrations, $\left[\mathrm{CO}_{3}{ }^{2-}\right]$, to fall, a phenomenon commonly referred to as ocean acidification (Caldeira \& Wickett, 2003; Orr et al., 2005). In the polar-regions, ocean acidification is further exacerbated by increased solubility of gases within colder waters (Fabry et al., 2009) and also by sea ice processes, which can amplify seasonal variability in saturation state of mixed layer waters (Fransson et al., 2013). Furthermore, increased ice melt is freshening the mixed layer, lowering Total Alkalinity (TA) and Dissolved Inorganic Carbon (DIC) concentration. Carbonate saturation of polar waters is rapidly falling to values where aragonite, the less stable form of calcium carbonate (Mucci, 1983), becomes susceptible to dissolution $\left(\Omega_{\mathrm{Ar}} \leq 1\right.$; Orr et al., 2005). Pteropods, or 'sea butterflies', are pelagic gastropods which have evolved 'wings' derived from the foot enabling them to swim. The delicate shells of pteropods are made of the metastable aragonite and thus may be particularly prone to dissolution.

The true polar pteropod, Limacina helicina, is a keystone species within polar ecosystems (Lalli \& Gilmar 1989; Comeau et al., 2009; Hunt et al., 2008; Hunt et al., 2010). Living in the upper few hundred meters of the water column, in waters which are becoming increasingly undersaturated with respect to aragonite, L. helicina is frequently presented as being the "canary in the coal mine" for ocean acidification (e.g. Orr et al., 2005). Incubation experiments, investigating the response of the Arctic sub-species L. helicina helicina (Hunt et al., 2010) to elevated $\mathrm{pCO}_{2}$ scenarios indicate reduced net calcification (Comeau et al., 2010) and degradation in shell condition in undersaturated waters (Lischka et al., 2011). Observations of living specimens collected from a region of upwelling in the Southern Ocean, suggest that Antarctic sub-species L. helicina antarctica (Hunt et al., 2010) is subject to extensive dissolution where $\Omega_{\mathrm{Ar}}=1$ (Bednarsek et al., 2012a). However, many species of mollusc thrive with undersaturated waters, for example within freshwater or deep-sea hydrothermal vent communities, on account of their calcareous shells being protected from dissolution by the presence of a protective organic coating, a periostracum, covering their shells (Taylor \& Kennedy, 1969; Harper, 1997). Possession of a periostracum is a shared 
character for all shelled molluscs (Harper, 1997). This thin organic sheet of the periostracum is secreted at the edge of the mantle and is the first formed layer of the shell. The primary function of the periostracum is to separate the site of calcification from the ambient water and to provide the initial template onto which the shell is crystallised. It is this isolation of the extrapallial space by the periostracum that allows calcification to occur within waters which are undersaturated with respect to carbonate, with extreme examples being the occurrence of molluscs within hydrothermal vent (e.g. Tunnicliffe et al., 2009) and freshwater environments (e.g. Harper, 1997). A secondary function of the periostracum is to provide a protective veneer shielding the shell from the corrosive effects of undersaturated waters or chemical attack from predators (Harper, 1997). Of critical note, since the periostracum is only formed at the actively growing shell margin (Saleuddin \& Petit 1983), thinning or loss of the periostracum via physical and biotic abrasion, epibiont erosion and bacterial decay will limit its effectiveness as protection as there is no possibility of repairing it once it is damaged.

Although there has been very little published on biomineralization in pteropods, it is clear from the shell microstructure (Bandel, 1990) that they follow the typical molluscan pattern. In the case of Limacina the shell is composed of well ordered crossed-lamellar and prismatic aragonite layers, internal to an ultra-thin $(<1 \mu \mathrm{m})$ periostracum (Sato-Okoshi et al., 2010). The findings of Bednarsek et al. (2012a, 2012b) seem to suggest that pteropods receive little benefit from their periostracum when exposed to undersaturated waters. Quantification of pteropod shell loss by Bednarsek et al (2014a), found that 14 day exposure to undersaturated waters $\left(\Omega_{\mathrm{Ar}}=0.8\right)$ resulted in a shell loss of $17.1 \% \pm 3.0 \%$. While the rate of dissolution reported by Bednarsek et al (2014a) is less than that predicted for the dissolution rate of pure aragonite, the fact that dissolution was reported over the entirety of the shells, questions the effectiveness of the periostracum for L. helicina antarctica. However, we note that Bednarsek et al. (Bednarsek et al., 2012a; Bednarsek et al., 2012c; Bednarsek et al., 2014b; Bednarsek et al., 2015) used chemical and plasma etching methods on shells prior to imaging, with the intention of removing the periostracum. Given the protective role of the periostracum in other shelled molluscs living in undersaturated waters, we opt to examine the relationship between dissolution and periostracal cover on specimens that are not subject to any preparation steps that would compromise the condition of the perioistracum or the shell beneath. Our minimal preparation approach intends to establish how effective the periostracum is in protecting the shells of pteropods. 
Here we present our observations of L. helicina helicina shells collected from the Greenland and Barents Seas in June 2012 and the result of a small scale incubation experiment to assess the effectiveness of the periostracum, and therefore vulnerability, of this species to ocean acidification in the Arctic.

\section{METHODS}

This study carried out observations and incubations on L. helicina helicina specimens recovered during routine motion-compensated plankton net deployments during research cruise JR271 on board RRS James Clark Ross in June-July 2012. L. helcinia helicina specimens were recovered at three sites within the Greenland and Barents Seas as detailed in Table 1 and Figure 1.

\section{Water column structure and chemistry and manipulation of seawater for incubation}

Vertical CTD profiles were performed to characterise important water column structure (temperature, salinity, Chl-a) and carbonate chemistry. The depth of water collection for the experimental setup was then determined based on these initial profiles. The unfiltered water was collected from dedicated CTD casts and transferred to acid-cleaned clear 1 L Duran bottles and then sealed pending carbonate chemistry manipulation and the addition of pteropods. Subsamples at time zero were taken directly from the CTD and immediately measured for Total Alkalinity (TA) and Dissolved Inorganic Carbon (DIC) to characterise the water column structure. DIC was analysed with an Apollo SciTech CT analyser (AS-C3), which uses a $\mathrm{CO}_{2}$ infrared detector (LICOR 7000). TA was determined using a semiclosedcell titration (Dickson et al., 2007) within the Apollo SciTech's AS-ALK2 Alkalinity Titrator. For both TA and DIC, the precision was $0.1 \%$ or better, with accuracy verified using certified reference materials (A.G. Dickson, Scripps). The remaining variables of the carbonate system were calculated with the CO2SYS programme (version 1.05, Lewis \& Wallace, 1998; Pierrot et al., 2006), using the constants of Mehrbach et al. (1973) refitted by Dickson \& Millero (1987). Carbonate chemistry in the experimental bottles was subsequently manipulated using equimolar additions of acid $\left(\mathrm{HCl}, 1 \mathrm{~mol} \mathrm{~L}^{-1}\right)$ and $\mathrm{HCO}_{3}^{-}\left(1 \mathrm{~mol} \mathrm{~L}^{-1}\right)$, as recommended by Gattuso et al. (2010) for increasing DIC at constant TA. The volumes of $\mathrm{HCl}$ and $\mathrm{HCO}^{-3}$ required to adjust $p \mathrm{CO}_{2}$ to the chosen target values $(650 \mu \mathrm{atm}, 800 \mu \mathrm{atm})$ 
were calculated from the measured ambient state of the carbonate system in seawater using CO2SYS. A further set of bottles remained unmanipulated (ambient). The bottles were sealed until the pteropods were added.

\section{Pteropod collection.}

A motion compensated Bongo net, with mesh sizes of $100 \mu \mathrm{m}$ and $200 \mu \mathrm{m}$ was deployed at dawn to $200 \mathrm{~m}$ below the sea surface and hauled vertically. Samples were gently transferred into a bucket of ambient seawater within which pteropods were found to settle to the bottom and could then be easily collected with a wide-mouthed plastic pipette. Visual examination of specimens under an Olympus SZX16 identified those that were actively swimming and had intact, fully translucent shells. Specimens that (i) had not yet developed wings (and moved via cilia), (ii) were winged but not actively swimming within one hour of collection or (iii) did not have fully translucent shells, were rinsed with $\mathrm{pH}$-buffed de-ionised water to induce mortality. Of these non-living specimens, all specimens within categories (i) and (ii) as well as a representative selection of category (iii) were preserved by air drying and stored in individual wells within specimen slides.

\section{Pteropod incubation}

Actively swimming juvenile specimens which appeared to have fully-translucent and intact shells were acclimatised to laboratory conditions in ambient seawater for about 4 hours as the incubation bottles were prepared. Five specimens were then randomly distributed into each of the three pre-prepared Duran bottles (see above). Six of the winged-specimens with fully translucent shells in which mortality was induced within one hour of collection were also incubated in ambient conditions and under elevated levels of $p \mathrm{CO}_{2}$ and were treated in an identical way to the actively swimming specimens to provide a control. These non-living specimens were divided between an additional three incubation bottles, two specimens per bottle.

Incubation bottles were stored in the dark within a cold room set to $\sim-1.5^{\circ} \mathrm{C}$, the same temperature as the ambient sea water within the mixed layer below the sea ice. During the incubation, bottles were inspected daily to ensure the living specimens were actively swimming. Each bottle was gently inverted, observed for several minutes and replaced. 
At the end of the 4 day incubation, a subsample of water was collected from each manipulated bottle for TA and DIC to determine the true $\mathrm{pCO}_{2}$ values achieved by the manipulation and also to determine the saturation state with respect to aragonite, $\Omega_{\mathrm{Ar}}$. Care was taken not to collect any pteropods in this water sample and not to generate any bubbles during the transfer. $5 \mathrm{ml}$ of this water was then removed from the sample, $250 \mu \mathrm{l}$ of mercuric chloride was added and the bottle was sealed prior to analysis. Following collection of the DIC and TA sample, water was gently decanted out of the Duran bottles into deep walled glass Petri dishes. Each full dish was inspected under the light microscope and pteropods were removed by gentle pipetting.

\section{Pteropod shell analysis}

Once all specimens were recovered from each treatment bottle, they were observed using an Olympus SZX16 with a mounted Canon D5 camera to document their vitality/mobility. All specimens were then individually rinsed in $\mathrm{pH}$-buffered ultra-pure water three times before being placed in a specimen slide and air-dried. Once dried, specimens were photographed again under the light microscope onboard, prior to storage for transport within air-tight containers containing silica-gel sachets.

Specimens were imaged under scanning electron microscope at the Natural History Museum, London. As the specimens were free of sea salts and dry, no preparation was required prior to imaging with a LEO 1455 variable pressure SEM. Higher magnification and resolution images were generated by use of the Ultra Plus SEM. Specimens were imaged without a coating using the Ultra Plus SEM, but the best images were generated by specimens coated in $\sim 10 \mathrm{~nm}$ of gold-palladium in a sputter-coater.

\section{RESULTS}

\section{Water column chemistry}

Temperature, salinity and $\Omega_{\mathrm{Ar}}$ as measured from CTD casts at each site (Table 1 ) are shown in Fig. 2. While the upper $200 \mathrm{~m}$ of the two open water sites in the Greenland Sea and the Barents Sea exhibit similar temperature and salinity profiles, typical of a well mixed upper water column, the Greenland Sea ice margin site exhibited strong thermo-halocline 
stratification above $200 \mathrm{~m}$. At the Greenland ice margin site, temperature decreased from $\sim 3^{\circ} \mathrm{C}$, similar to the open ocean water sites to $\sim-1.6^{\circ} \mathrm{C}$ beneath the sea ice within the upper $200 \mathrm{~m}$. Freshening of the surface water column due to sea ice melt was also evident, with salinity falling below 33 within the upper $20 \mathrm{~m}$. While $\Omega_{\mathrm{Ar}}$ values at the Greenland Sea ice margin were the lowest measured within the scientific cruise (Tyrrell et al., this issue), $\Omega_{\mathrm{Ar}}$ exceeded 1 at all three sites, meaning that the water column at each site was oversaturated with respect to aragonite at the time of measurement.

\section{Specimens recovered}

At the Greenland Sea ice margin, 56 specimens of L. helicina helicina were recovered in the two deployments of the Bongo net. Analysis of their maximum shell diameter identified two distinct cohorts of L. helicina helicina at the Greenland Sea ice margin (Fig 3). The smaller cohort had an average maximum shell diameter of $202 \pm 35 \mu \mathrm{m}(\mathrm{n}=20)$. These specimens were veligers that had developed one whorl (Fig. $4 \mathrm{~V} 1$ and V2) and were ciliated, having not yet developed wings. The larger cohort, consisting of juveniles, had an average maximum shell diameter of $1255 \pm 146 \mu \mathrm{m}$ ( $\mathrm{n}=36$ ), and had typically developed 3-4 whorls (Fig. $4 \mathrm{~J}$ 1J6). The juvenile specimens had also developed wings, were active swimmers, and were far more agile than the veligers.

Further specimens of L. helicina helicina, including 20 adults with maximum shell diameters ranging in size from 4.8 to $8.2 \mathrm{~mm}$, were recovered from the Greenland Sea and Barents Sea open water sites to the east on the $21^{\text {st }}$ and $23^{\text {rd }}$ of June 2015 (Fig. 1).

\section{Shell analysis}

On board, light microscope examination of specimens collected at the open water sites (Greenland Sea and Barents Sea) found all shells were fully translucent. Although evidence of fracture and regrowth was apparent in several shells recovered from both of these sites (Fig. 5), the shell on both sides of the fracture remained fully translucent. At the Greenland Sea ice margin, all veligers also exhibited fully-translucent shells (Fig. 4, V1-2), but juvenile specimens did not all present fully translucent shells (Fig. 4, J1-2) with 13 out of 36 juveniles exhibiting areas of shell that appeared opaque under light microscope (Fig. 4, J3-6). Three of these specimens presented deep damage to the shell surface (Fig. 4, J5- 6). Investigation of 
areas which appeared to be opaque under light microscope with SEM revealed three types of shell damage.

\section{(i) Central whorls}

$85 \%$ of the damaged juveniles recovered from the Greenland Sea ice margin exhibited damage to the central whorl. SEM analysis showed that the areas of opaque shell within the central whorl of $\mathrm{J} 3$ and $\mathrm{J} 4$ corresponded to regions of finely pitted surface texture through to fully exposed aragonite crystals (Fig. 6).

\section{(ii) Deep damage}

$23 \%$ of the damaged juveniles recovered from the Greenland Sea ice margin exhibited deep damage to their shell, meaning that although the shell was not observed to be perforated, dissolution appeared to have removed at least one layer of aragonite. In the case of J5 (Fig. 7 b-e) and J6 (Fig. 8 b-e), deeper damage to the shell was clearly identifiable under SEM with extensive exposure of multiple aragonite layers visible. The progressive exposure of numerous layers of aragonite was evident in both specimens to a depth that exceeded the thickness of the original shell (Fig. 7a). In each case the margin between the area of exposed aragonite and translucent, smooth shell was abrupt. The growth of the subsequent whorls can be seen to mould around the deep damage of inner whorls (Fig. 7e, Fig. 8c).

\section{(iii) Fracture zones}

$62 \%$ of the damaged specimens removed from the Greenland Sea ice margin exhibited fracture zone damage. SEM analysis of opaque linear features extending across the whorls of J5 and J6 revealed dissolution of aragonite along a fracture of the original shell and subsequent growth of new shell (Fig. 7a, b, f, g, and Fig, 8a, b, e and f). With J5 it appears that dissolution at the fracture zone is restricted to the new shell (Fig. $7 \mathrm{f}, \mathrm{g}$ ). Under high magnification using the Ultra Plus SEM, the area of exposed aragonite crystals on the new section of shell (closest to the fracture) clearly revealed a loose section of a filmy layer that appeared to extend across the new, fully opaque section of shell, but was not present over the area of exposed aragonite (Fig. 7g, h). On J6, the dissolution appeared to be concentrated on the old shell side of the fracture (Fig. 8 e, f). The uncoated specimens within the Ultra Plus SEM did not generate such crisp images as the coated specimens, but nonetheless a filmy 
layer with perforations overlaying what appear to be vertically stacked, partially eroded aragonite crystals can be seen (Fig. 8f).

\section{Incubations}

Actively swimming specimens of L. helicina with fully translucent shells collected from the Greenland Sea ice margin on June $18^{\text {th }} 2012$ were incubated for 4 days under the treatments shown in Table 2.

Although the simulated $p \mathrm{CO}_{2}$ manipulations did not achieve their target values, both sets of treatments $(650 \mu \mathrm{atm}$ and $800 \mu \mathrm{atm})$ resulted in conditions undersaturated with respect to aragonite, with $\Omega_{\mathrm{Ar}}$ values of 0.76 and 0.63 respectively. After four days of incubation, there were no fatalities in any of the treatments.

Inspection of the shells at the end of the incubation revealed that all shells within the ambient treatment $(n=5)$ remained fully translucent (Fig 9a). At the end of the incubations in which $p \mathrm{CO}_{2}$ was elevated, opaque regions to the shell had developed in 2 of the 5 specimens at a target $p \mathrm{CO}_{2}$ of $650 \mu \mathrm{atm}$ (Fig. 9b), and 3 of the 5 specimens at a target $p \mathrm{CO}_{2}$ of $800 \mu \mathrm{atm}$ (Fig. 9c). These opaque areas were superficial, compared to the damage observed in the 13 non-pristine specimens recovered from the Greenland Sea ice margin.

The shells of non-living specimens that were incubated with ambient water and at a target $p \mathrm{CO}_{2}$ of $650 \mu \mathrm{atm}$ (Fig. 9d and e respectively) for 4 days became uniformly opaque.

\section{DISCUSSION}

We observed naturally occurring dissolution to the juvenile shells of L. helicina helicina recovered at the Greenland Sea ice margin. It is evident that shell dissolution is exclusively associated with areas where damage to the protective periostracal sheet has been sustaining during the animal's life. Some areas of damage extend deeper than the original thickness of the shell, indicating that the animals respond to shell damage by secreting aragonite internally to maintain their shells. Where the periostracum remained fully intact, the shell appears pristine (fully translucent) with no sign of dissolution. Recently acquired periostracal damage associated with collection, becomes evident by the early stages of shell dissolution after four days of incubation, but only in waters $\Omega_{\mathrm{Ar}}<1$. 
As is typical of the sampling protocol used in these studies, we acknowledge that our sample size, $n=56$ at the Greenland Sea ice margin, is not ideal, but exceeds the statistical minimum. Furthermore, the number of specimens analysed in this study considerably exceeds those of Bednarsek et al. 2012c ( $\mathrm{n}=3$ to 20$)$ and Bednarsek et al. 2014b $(n=10)$.

Our study confirms that pteropods are protected from natural dissolution by their periostracum in the same way that other shelled molluscs are, and that their shells only become vulnerable when the periostracal cover is breached. We now consider how these patterns of dissolution relate to the life-history of L. helicina helicina and the likely causes of periostracum damage and subsequent shell dissolution in their natural environment.

\section{Population dynamics}

Since shell damage and dissolution were only observed in the juvenile specimens of $L$. helicina helicina we first of all consider the life stages represented by the two cohorts. Two modal peaks in maximum shell diameter, $200 \mu \mathrm{m}$ and $1380 \mu \mathrm{m}$, were observed within $L$. helicina helicina collected at the Greenland Sea ice margin. We consider the smaller, ciliated specimens to represent veligers of the 2012 recruitment (Fig. 2, V1-2), likely spawned in the spring, and the larger winged specimens to represent juveniles that overwintered from the 2011 recruitment (Fig. 2, J1-J6), fitting the ontogenetic-size classifications of Lalli \& Wells (1978).

\section{Shell growth and protection.}

Although it is very thin, our results indicate that the pteropod periostracum, when intact, protects the underlying aragonite from dissolution by shielding it from exposure to sea water. However, should the periostracum of a pteropod become perforated, the shell beneath will become exposed and susceptible to dissolution if the environment is undersaturated with respect to carbonate. This scenario is evidenced by our observations following the 4 day incubation of shells that were pristine prior to incubation. At the end of the incubation, $50 \%$ of the specimens incubated at $\Omega_{\mathrm{Ar}}<1$ exhibited surface scarring under light microscope (Fig. $9 \mathrm{~b}, \mathrm{c})$ that was localised exclusively to obvious scratch-like marking. All specimens incubated within ambient waters appeared pristine (Fig. 9a). The absence of scratches on any of the specimens incubated within ambient waters $\left(\Omega_{\mathrm{Ar}}=1.32\right)$ indicates that either none of 
the specimens in this treatment received scratches during collection, or they were scratched but no dissolution occurred since the water was oversaturated with respect to aragonite. We consider it unlikely that none of the 5 specimens incubated in ambient waters received any superficial damage to their periostracum and therefore conclude that our incubation results indicate that dissolution of the shell will only be observed under the following circumstances. Firstly, dissolution will only occur localised to sites where the protective seal of the periostracum is broken and aragonite and waters are in direct contact. Secondly, exposed aragonite will only dissolve, and allow the scarring to become visible, when the shell is exposed to undersaturated waters. Damage to the periostracum and exposure to undersaturated waters are both necessary for shell dissolution in L. helicina helicina to occur.

Considering these two contributing factors we now consider our observations of living specimens of L. helicina helicina recovered from the Greenland Sea ice margin in the context of 1 . how the periostracum may have become damaged and 2. where and when the juvenile specimens became exposed to undersaturated waters.

\section{Damage to the periostracum}

Looking first at all at the pattern and distribution of dissolution exhibited on shells of $L$. helicina helicina we consider the following hypotheses for how the perisotracum may have become compromised.

\section{(i) Central whorl damage}

The periostracum of the initial whorl/protoconch appears to have been particularly susceptible to damage. The pitted texture observed in the centre of J3-6 does not exhibit any particular pattern indicative of mechanical damage. Being the oldest part of shell, it has been exposed to abrasion and/or microbial erosion for the longest time and is therefore more prone to loss or damage. It is also worth noting that although the mineralogy of Limacina protoconchs have not been studied, those of some other gastropods have been shown to include Amorphous Calcium Carbonate (Auzoux-Bordenave et al. 2010; Auzoux-Bordenave et al. 2015) which is more unstable than aragonite and may be particularly prone to dissolution. Mussel shells grown within waters of $\mathrm{pH}=7.2$ also exhibited a similar pattern of shell damage whereby dissolution only occurred where the periostracum at the umbo, the 
oldest part of the shell, had been abraded owing to adjacent mussels rubbing together (Rodolpho-Metalpa et al., 2011).

\section{(i) Deep damage}

Exposure of multiple layers of aragonite crystals appears within the $2^{\text {nd }}$ and $3^{\text {rd }}$ whorls of specimens J5 and J6. The original cause of the breach to the periostracum may be mechanical or through erosion of the periostracum by epibiont activity. However, in the case of J6, linear features to the areas of deep damage suggest a mechanical origin.

While the animal can generate aragonite internally to patch up areas of shell damage (McMahon and Bogan, 2001), it cannot repair damage to the periostracum (Saleuddin \& Petit 1983 ) and the exposed aragonite beneath will always be susceptible to dissolution if $\Omega_{\mathrm{Ar}}$ falls below 1 . The exposure of multiple layers of aragonite, exceeding the thickness of the original shell, suggests that the animals repaired their shells internally by patching up areas of deep damage with new aragonite secreted on the inner wall of the shell. Again, since the pteropod is unable to replace the periostracum and protect the newly precipitated aragonite, this area of repair will continue to be dissolved from the outside so long as it is exposed to undersaturated waters. In this way the areas of deep damage we observe can significantly exceed the thickness of the original shell. Internal repair of this type is frequently observed in other molluscs, such as Harper et al. (2012). Knowing the linear extension rate of L. helicina helicina would allow the depth of the moulding of the subsequent whorls around deep damage of an inner whorl to determine the rate of dissolution of the exposed shell.

\section{(ii) Fracture zones}

Only $2 \%$ of the sub-Antarctic population of $L$. helicina antarctica survive the first year (Bednarsek et al., 2012c), presumably, largely due to predation. While larger predators such as fish will eat the entire animal, a principal predator of L. helicina, is the non-shelled (gymnosomatus) pteropod Clione limacina, which will attach itself to the prey's shell and extract the animal from within (Lalli \& Gilmer, 1989). In a bid to protect itself, L. helicina will retract within its shell but, in doing so, risks damage to the most newly formed, outer edge of its shell during failed predation attempts. The distinctive fracture zones reported here are indicative of the shell aperture having been broken at some point in the past and 
subsequently repaired and are similar to failed predation scars found on other gastropods (Alexander \& Dietl, 2003). Scratch-like markings perpendicular to the fracture line, frequently observed on specimens recovered from the Greenland Sea ice margin (Fig 10) may indicate C. limacina predation attempts. The damage caused to L. helicina during such predation attempts appears to be readily recoverable and subsequent regrowth of new 'pristine' shell from broken apertures is commonly observed (Fig. 5, 7, 8, 10; Lischka \& Riebesell, 2012; Comeau et al., 2012; Bednarsek et al., 2012a [supplementary Fig. 2]). While in the ciliated, veliger stage, the animal is less agile and it is likely that predation attempts at this stage are highly successful which explains why none of the veligers showed failed predation damage. Animals that survive this first season to become fully-winged juveniles become better able to evade predation attempts. What is unique to the specimens collected in the Greenland Sea ice margin is frequent occurrence of dissolution localised to fractures and surface damage. The suture between the damaged shell and regrowth appears to be particularly prone to dissolution. SEM images (Fig. 7 and 8) suggest that the incomplete merger of old fractured periostracum and new periostracum grown at the aperture edge may allow a thin band of aragonite to become exposed and dissolved in when undersaturated waters, which can undermine the periostracum adjacent to the breach. Animals that survive the first year will carry the scars of predatory damage into later life.

\section{Exposure to understaturated waters}

At the time of collection, the entire depth of the water column at the Greenland Sea ice margin was over-saturated with respect to aragonite (Fig. 2). At these $\Omega_{\mathrm{Ar}}$ values we would not expect to observe any signs of shell dissolution, as is the case at the open water sites in the Greenland and Barents Sea and the pristine specimens incubated in ambient waters from the Greenland Sea ice margin. Furthermore, the absence of any damage observed on the veligers, which were likely to have been spawned just weeks earlier, is consistent with them growing in supersaturated waters. However, the high incidence of shell damage to the 2011 recruitment suggests that these specimens had been exposed to lower $\Omega_{\mathrm{Ar}}$ at some point within the last year. In April 2010, Comeau et al. (2012) collected L. helicina helicina below first year sea ice in the Canadian Arctic. In this $~ 350 \mathrm{~m}$ water depth shelf setting, specimens were recovered from the upper $200 \mathrm{~m}$ of the water column where $\Omega_{\mathrm{Ar}}$ was found to vary between 1.07 and 1.40. These $\Omega_{\text {Ar }}$ values are similar to measurements collected beneath sea ice in the Amundsen Gulf, Arctic Sea, in April 2008 (Fransson et al., 2013). Fransson et al. 
419 (2013) observed the lowest $\Omega_{\mathrm{Ar}}$ beneath Arctic sea ice water during April following the

420

421

422

423

424

425

426

427

428

429

430

431

432 accumulation of $\mathrm{CO}_{2}$-enriched brines expulsed into sub-sea ice waters during sea ice formation through the winter months in addition to $\mathrm{CO}_{2}$ produced by the remineralisation of organic matter beneath the sea ice (Chierici et al., 2011). By May, the release of $\mathrm{CO}_{2}$ depleted melt water and the onset of photosynthesis reduced dissolved $\mathrm{CO}_{2}$ concentrations in the mixed layer waters, thus increasing $\left[\mathrm{CO}_{3}{ }^{2-}\right]$ and $\mathrm{pH}$ and seeing $\Omega_{\mathrm{Ar}}$ reaching values of up to 2 (Fransson et al., 2013). Assuming similar processes control under sea ice waters within the Greenland Sea, we anticipate that $\Omega_{\text {Ar }}$ would have been lower during the winter months of 2011/2012 than observed in June 2012 when sea ice melt was underway and phytoplankton production was well established. We illustrate our proposed life history, including failed predation, shell repair and regrowth and subsequent dissolution in undersaturated waters over winter in Figure 11.

\section{Dead animal shell dissolution}

We observed that the shells of dead specimens dissolved uniformly (cf. Gerdherdt \& Henrich, 2001). We propose that the shells of dead specimens, with a fully intact periostracum, dissolve from the inside (cf. Tunnicliffe et al., 2009). Degradation of the animal's body would lower the saturation state internally, so regardless of the saturation state of the surrounding water, the shell is vulnerable to dissolution once the animal is dead. This may account for the sparse occurrence of pteropods within seafloor sediments, even those above the lysocline (Hunt et al., 2008).

\section{Effect of dissolution on animal health}

Regrowth and internal repair of the shell demonstrates the ability of L. helicina helicina to maintain shell integrity following trauma. In fact the animals that exhibited extensive areas of deep dissolution were not markedly smaller than those with pristine shells. However, energy required to repair the shell from the inside may have a somatic or reproductive cost. This is seen in other species of mollusc exposed to elevated $p \mathrm{CO}_{2}$ conditions (Wood et al., 2008; 2010)

\section{Removal of periostracum prior to visual inspection}

Our observation of discrete regions of shell dissolution, localised to areas of periostracum damage is consistent with observations on larger mollusc shells (Tunnicliffe et al., 2009; 
Rodolfa-Metalpa et al., 2011; Garilli et al., 2015), but contrary to the findings of Bednarsek et al. (2012a) who report dissolution over the entirety of L. helicina antarctica shells in a region of upwelling in the Southern Ocean. Bednarsek et al. (2012a) noted that the dissolution

452 response they report is similar to that of dead animals incubated at $\Omega_{\mathrm{Ar}}=1$ (Byrne et al., 1984; Feely et al., 1988) and claimed that this was evidence that pteropods 'have little to protect themselves from $\Omega_{\mathrm{Ar}}$ under-saturation'. Our study, however, raises concerns about the preparation methods used in studies of live-collected material. As previously demonstrated by Lischka et al. (2011), Lischka \& Riebesell (2012a), and Comeau et al. (2012), we show that dissolution of pteropod shells is readily evident under light microscope. The use of SEM images provides context to the nature and pattern of the dissolution. Bednarsek et al. (2012a) do not provide any light microscope images and use an extensive method to prepare specimens for SEM analysis (detailed in Bednarsek et al., 2012b) meaning it has not been possible to directly compare our observations. Furthermore, since these are two subspecies, identical treatment of samples would be necessary to ensure any species-specific responses are accurately observed. We therefore highlight the need for uniformity of approach, also for techniques to be employed that do not involve chemical reaction or plasma etching with the outer shell layers. Wholesale removal of the periostracum inhibits recognition between dissolution which has occurred to the living specimen due to natural damage to the periostracum, as opposed to 'bleaching' of shells prior to analysis which can cause postmortem damage to the crystalline fabric of the shells. The latter is particularly important as it is well known that shell microstructures contain both inter and intracrystalline organic matrix (Marin et al 1996), the selective removal of which may produce a corroded appearance (see Peck et al., 2015) which may be misinterpreted. We encourage the development of protocols that allow for dissolution to be documented and quantified using minimal preparation, in particular avoiding chemical treatment of the shell surface.

\section{Conclusions}

For molluscs (Tunnicliffe et al., 2009) and other genera (Rodolfo-Metalpa. et al., 2011; Ries et al., 2009) living in under-saturated waters, the periostracum, an organic external layer provides a vital means of protecting the shells and exoskeletons from dissolution and therefore ensuring the vitality of the animal. The effectiveness of the periostracum to pteropods however has been brought into question in recent years (Bednarsek et al., 2012a; Bednarsek et al., 2014a). We demonstrate that, in L. helicina helicina, shell dissolution can 
507 Alexander, R. \& Dietl, G. 2003. The fossil record of shell-breaking predation on marine bivalves 508 509

occur where the periostracum has been breached. Where the periostracum has remained intact however, the shell appears pristine with no sign of dissolution, even when exposed to $\Omega_{\mathrm{Ar}} \leq 1$. Since the periostracum appears to offer such effective protection of the shell we propose that the extent of shell dissolution is not a direct function of exposure to undersatutrated waters, rather it is dependent on the extent of periostracal damage and exposure to undersaturated waters. In addition to being able to protect their shells from whole scale dissolution, where localised dissolution has occurred due to trauma to the periostracum the shell may become thicker than the original shell, indicating that the animal is able to secrete layers of aragonite internally to patch up localised damage. Furthermore, our observations support rinsing and drying specimens on collection to enable shell damage to be identified with light microscopy (Lischka et al., 2011), and we caution against the use of chemical or laser etching of the periostracum before visual analysis.

While we propose that L. helicina helicina are perhaps not as vulnerable to ocean acidification as previously claimed, at least not from direct shell dissolution, we have not assessed the energetic consequences of calcifying a shell in under saturated waters and repairing and maintaining a damaged shell within waters of $\Omega_{\mathrm{Ar}} \leq 1$. Further investigation into the long term reproductive and somatic consequences of ocean acidification are needed.

\section{Acknowledgements}

We thank the captains and crew of the RRS James Clark Ross for enabling this research to be carried out, and PSO Ray Leaky. We are grateful for funding support from NERC, Defra and DECC to the pelagic consortium of the UK Ocean Acidification programme (grant no. NE/H017348/1*). Thank you to Alex Ball and Tomasz Goral at the Natural History Museum for assisting with SEM imaging.

\section{References} and gastropods, in 'Predator Prey Interactions in the Fossil Record', Springer, pp. 141176. 
510 Auzoux-Bordenave, S., Badou, A., Gaume, B., et al. 2010. Ultrastructure, chemistry and 511 mineralogy of the growing shell of the European abalone Haliotis tuberculata. Journal of $512 \quad$ Structural biology 171, 277-290.

513 Auzoux-Bordenave S, Brahmi C, Badou A, et al. 2015. Shell growth, microstructure and 514 composition over the development cycle of the European abalone Haliotis tuberculata. $515 \quad$ Marine Biology 162, 687-697.

516 Bandel, K.1990. Shell structure of the gastropoda excluding archaegastropoda. In: Carter, J.G. 517 (Ed.), Skeletal Biomineralization: Patterns, Processes, and Evolutionary Trends, Vol. 1. Van Nostrand Reinhold, New York, pp. 1-832.

519Bednaršek, N., Tarling, G.A., Bakker, D.C.E., et al. 2014a. Dissolution dominating calcification 520 process in polar pteropods close to the point of aragonite undersaturation. PLoS ONE, 5219 9(10), e109183, doi: 10.1371/journal.pone.0109183.

522Bednaršek, N., Feely, R.A., Reum, J.C.P., et al. 2014b. Limacina helicina shell dissolution as an 523 indicator of declining habitat suitability due to ocean acidification in the California 524 Current Ecosystem. Proc. Roy. Soc. B, 281, 20140123, doi: 10.1098/rspb.2014.0123. 525Bednaršek, N., et al., 2012a. Description and quantification of pteropod shell dissolution: a 526 sensitive bioindicator of ocean acidification. Glob. Change Biol. 18, 2378-2388. 527 doi:10.1111/j.1365-2486.2012.02668.x)

528Bednarsek, N., et al., 2012b, Population dynamics and biogeochemical significance of Limacina 529 helicina antarctica in the Scotia Sea (Southern Ocean). Deep-Sea Research II, 59-60, $530 \quad 105-116$.

531Bednarsek, N., et al. 2012c. Extensive dissolution of live pteropods in the Southern Ocean. Nat. 532 Geosci. 5, 881-885. doi:10.1038/ngeo1635.

533Bednaršek, N., Možina, J., Vogt, M., et al., 2012d. The global distribution of pteropods and their 534 contribution to carbonate and carbon biomass in the modern ocean. Earth Syst. Sci. Data, 535 4, 167-186, doi: 10.5194/essd-4-167-2012.

536Byrne, R.H., J.G. Acker, P.R. Betzer, R.A. Feely, and M.H. Cates. 1984. Water column 537 dissolution of aragonite in the Pacific Ocean. Nature, 312, 321-326 538Caldeira, K. \& Wickett, M.E. 2003. Anthropogenic carbon and ocean pH. Nature 425, 365. 539Chierici, M., Fransson, A. Lansard, B., et al. 2011. The impact of biogeochemical processes and 540 environmental factors on the calcium carbonate saturation state in the circumpolar flaw 
541 lead in the Amundsen Gulf, Arctic Ocean. J. Geophys. Res., 116, C00G09, doi:10.1029/2011JC007184.

543Comeau S, Alliouane S, Gattuso JP. 2012. Effects of ocean acidification on overwintering $544 \quad$ juvenile Arctic pteropods Limacina helicina. Marine Ecology Progress Series 456: 279545 284. doi: $10.3354 /$ meps09696

546Comeau, S., Gorsky, G., Jeffree, R., et al. 2009. Impact of ocean acidification on a key Arctic 547 pelagic mollusc (Limacina helicina). Biogeosciences, 6 (9): 1877. doi:10.5194/bg-6$548 \quad 1877-2009$.

549Comeau S, Jeffree R, Teyssié JL, Gattuso JP. 2010. Response of the Arctic pteropod Limacina $550 \quad$ helicina to projected future environmental conditions. PLoS ONE 5:e11362 551Dickson, A. G. \& Millero, F. J. 1987. A comparison of the equilibrium constants for the 552 dissociation of carbonic acid in seawater media. Deep-Sea Res Part A, 34, 1733-1743. 553Dickson AG, Sabine CL, Christian JR (eds). 2007. Guide tobest practices for CO2 554 measurements. PICES Special Publication 3, PICES, Sidney, BC 555Fabry, V.J., J.B. McClintock, J.T. Mathis, \& J.M. Grebmeier. 2009. Ocean acidification at high 556 latitudes: The bellwether. Oceanography 22(4), 60-171

557Feely, R.A. et al. 1988. Winter-summer variations of calcite and aragonite saturation in the 558 northeast Pacific. Mar. Chem., 25, 227-241

559Fransson, A., Chierici, M., Miller, L.A., et al. 2013. Impact Of Sea-Ice Processes On The 560 Carbonate System And Ocean Acidification At The Ice-Water Interface Of The 561 Amundsen Gulf, Arctic Ocean. Journal of Geophysical Research: Oceans, 1, pp.1-81 562Gannefors, C., Böer, M., Kattner, G., et al. 2005. The Arctic sea butterfly Limacina helicina: 563 Lipids and life strategy. Marine Biology, 147, 169. doi:10.1007/s00227-004-1544-y. 564Garilli, V., Rodolfo-Metalpa, R., Scuderi, D., et al. 2015. Physiological advantages of dwarfing 565 in surviving extinctions in high-CO2 oceans. Nature Climate Change, 566 doi:10.1038/NCLIMATE2616

567Gattuso JP, Gao K, Lee K, Rost B, and Schulz KG. 2010. Approaches and tools to manipulate 568 the carbonate chemistry.In: Riebesell U, Fabry VJ, Hansson L, Gattuso JP(eds) Guide to 569 best practices for ocean acidification research and data reporting. Publications Office of 570 the European Union, Luxembourg, p 243-258

571Gerhardt, S. \& Henrich, R. 2001. Shell preservation of Limacina inflate (Pteropoda) in surface 572 sediments from the Central and South Atlantic Ocean: a new proxy to determine the 573 aragonite saturation state of water masses, Deep-Sea Res. I, 48, 2051-2071. 
574Harper, E. M. 1997. The molluscan periostracum: an important constraint in bivalve evolution. 575 Palaeontology, 40, 71-97.

576Harper, E.M., Clark, M.S., Hoffman, J. I et al. 2012. Iceberg scour and shell damage in the $577 \quad$ Antarctic bivalve Laternula elliptica. PLoS One, 7 (9). e46341

578Hunt B., et al., 2008. Pteropods in Southern Ocean ecosystems. Progress in Oceanography, 78, $579 \quad 193-221$.

580Hunt, B., Strugnell, J., Bednarsek, N., et al. 2010. Poles apart: the "bipolar" pteropod species 581 Limacina helicina is genetically distinct between the Arctic and Antarctic oceans Plos $582 \quad$ One e9835.

583Lalli, C.M., \& Gilmer R.W. 1989. Pelagic Snails: The Biology of Holoplanktonic Gastropod 584 Mollusks, Stanford University Press, Stanford, CA, USA.

585Lalli, C.M. \& Wells, F.E., 1978. Reproduction in the genus Limacina (Opisthobranchia:

586 Thecosomata). Journal of Zoology (London) 186, 95-108.

587Lewis E, \& Wallace DWR. 1998. Program developed for CO2 system calculations. Technical 588 Report ORNL/CDIAC-105. Carbon Dioxide Information Analysis Center, Oak Ridge 589 National Laboratory, USDepartment of Energy, Oak Ridge, TN, USA.

590Lischka S, Büdenbender J, Boxhammer T, Riebesell U. 2012. Impact of ocean acidification and 591 elevated temperatures on early juveniles of the polar shelled pteropod Limacina helicina: 592 mortality, shell degradation, and shell growth. Biogeosciences, 8, 919-932.

593Lischka, S. \&Riebesell U. 2012 Synergistic effects of ocean acidification and warming on 594 overwintering pteropods in the Arctic. Glob. Change Biol. 18, 3517-3528. doi:10.1111/ 595 gcb.12020)

596Lischka S, Budenbender J, Boxhammer T, Riebesell U. 2011. Impact of ocean acidification and 597 elevated temperatures on early juveniles of the polar shelled pteropod Limacina helicina: 598 mortality, shell degradation, and shell growth. Biogeosciences 8: 919-932. doi:

$599 \quad 10.5194 /$ bg-8-919-2011.

600Marin, F., Smith, M., Isa, Y., Muyzer, G., Westbroek, P. 1996. Skeletal Matrices, muci, and the 601 origin of invertebrate calcification. Proceedings of the National Academy of Sciences of 602 the United States of America 93 1554-1559

603McMahon R.F. \& Bogan A.E. 2001. - Ecology and classification of North American freshwater 604 invertebrates. Pages 331-429 in Mollusca: Bivalvia ( $2^{\text {nd }}$ edition). Thorp J.H. \& Covich 605 A.P. (eds). Academic Press, San Diego 
606McNeil B. I., \& Matear R. J. 2008. Southern Ocean acidification: A tipping point at 450-ppm 607 atmospheric CO2. Proc Natl Acad Sci USA, 105, 18860-18864.

608Mehrbach, C., Ch. Culberso, J.E. Hawley, and Rm. Pytkowic. 1973. Measurement of apparent 609 dissociation constants of carbonic acid in seawater at atmospheric pressure. Limnol. $610 \quad$ Oceanogr. 18, 897-907.

611Mucci, A. 1983. The solubility of calcite and aragonite in seawater at various salinities, 612 temperatures and one atmosphere total pressure. Am. J. Sci. 28, 780-799.

613Orr J.C., Fabry, Aumont, V.J. et al. 2005. Anthropogenic ocean acidification over the twenty-first 614 century and its impact on calcifying organisms. Nature, 437: doi: 10.1038/nature04095 615Peck, L. S., Clark, M., Power, D., et al. 2015 Acidification effects on biofouling communities: 616 winners and losers. Global Change Biology, doi: 10.1111/gcb.12841

617Pierrot, D. E. L. \& Wallace, D. W. R. 2006. MS Excel program developed for CO2 System 618 Calculations. ORNL/CDIAC-105, Oak Ridge, Tennessee, Carbon Dioxide Information 619 Analysis Center, Oak Ridge National Laboratory, US Department of Energy. 620Ries J.B., Cohen, A. L., McCorkle, D. C. 2009. Marine calcifiers exhibit mixed responses to $621 \mathrm{CO}_{2}$-induced ocean acidification. Geology, 37, 1131-1134.

622Rodolfo-Metalpa, R., Houlbreque, F., Tambutte, E., et al. 2011. Coral and mollusk resistance to 623 ocean acidification adversely affected by warming. Nature Climate Change, 1, 308-312. 624Sabine, C. L., Feely, R. A., Gruber, N., et al. 2004. The Oceanic Sink for Anthropogenic $\mathrm{CO}_{2}$. $625 \quad$ Science, $305,367-371$.

626Saleuddin, A. S. M., \& Petit, H.P. 1983. The mode of formation and the structure of the 627 periostracum. In: Saleuddin ASM, Wilbur KM editors. The Mollusca. Vol. 4: Physiology 628 Part I. New York: Academic Press. 199-234.

629Sato-Okoshi W, Okoshi K, Sasaki H, Akiha F., 2010. Shell structure characteristics of pelagic 630 and benthic molluscs from Antarctic waters. Polar Science, 4, 257-261.

631Taylor, J. D., and Kennedy, W. J. 1969. The influence of the periostracum on the shell structure 632 of bivalve molluscs. Calc. Tiss. Res. 3, 274-283

633Tunnicliffe, V., Davies K. T., Butterfield, D. A., Embley, R.W., Rose, J. M., and W. W. 634 Chadwick, W. W. Jr., 2009. Survival of mussels in extremely acidic waters on a 635 submarine volcano. Nature Geosciences, 2, 344-348. DOI: 10.1038/NGEO500 636Wood, H.L., Spicer, J.I., Widdicombe, S. 2008. Ocean acidification may increase calcification 637 rates, but at a cost. Proceedings of the Royal Society B: Biological Sciences 275.1644, 638 767-1773. 
639Wood, H. L., et al. 2010. Interaction of ocean acidification and temperature; the high cost of survival in the brittlestar Ophiura ophiura. Marine Biology, 157, 2001-2013.

Figure 1. Location of the three sites referred to in this study and sea ice coverage on June $18^{\text {th }}$ 2012. Greenland Sea ice margin site, orange; Greenland open water site, dark blue; Barents Sea site, light blue.

Figure 2. Water column profiles of temperature, salinity and $\Omega_{\mathrm{Ar}}$ at the three sites

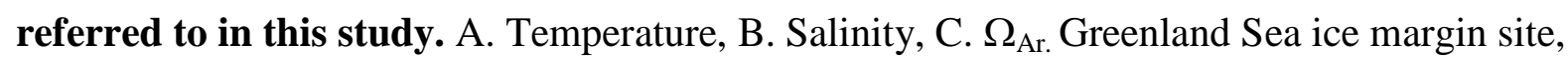
orange; Greenland open water site, dark blue; Barents Sea site, light blue. Dotted line at 200 $m$ indicated the depth from which the Bongo next was vertically hauled. recovered from the Greenland Sea ice margin. Two distinct cohorts of ciliated veligers and winged juveniles were observed. Greenland Sea ice margin. V1-2 are veligers from the 2012 recruitment (scale bars 100 $\mu \mathrm{m})$. J1-6 juveniles from the 2011 recruitment (scale bars $250 \mu \mathrm{m}$ ). J1-2, exhibit fully translucent/pristine shells. J3-4, exhibit some areas of opaque shell, but no deep damage. J56 , exhibit areas of opaque shell with some deep damage.

Figure 5. Light microscope images of examples of $L$. helicina helicina from the open water sites in the Greenland Sea and Barents Sea exhibiting fracture and repair but no areas of opaque shell.

Figure 6. Light microscope and SEM images of J3 (a, b, c; LEO) and J4 (d, e, f; Ultra Plus [uncoated]).

Figure 7. Light microscope and Ultra Plus (coated) SEM images of J5. C-E, focus on an area of deep damage in the third whorl. In $\mathrm{C}$ and $\mathrm{E}$ note how the fourth whorl moulds around the deep damage of the third whorl. In D note how multiple layers of aragonite have been exposed and how deep damage exceeds the depth of the original shell, B. F, G and $\mathrm{H}$ focus on a fracture in the third whorl. F shows a neat suture between old shell, below the fracture, 
and new shell above. Moving along the fracture, G, aragonite crystals become exposed where the suture between the periostracum of the old and new shell was not adequate to protect the shell beneath and dissolution has occurred. The area circled in $\mathrm{G}$ is shown in $\mathrm{H}$. A piece of periostracum that has become loose as under-saturated waters have undermined the periostracum from the suture and dissolved the shell from beneath it.

Figure 8. Light microscope and Ultra Plus (uncoated) SEM images of J6. C and D focus on areas of deep damage in the third whorl. Note that multiple layers of aragonite are exposed and how the fourth whorl moulds around the deep damage of the third whorl. E and F focus on a fracture in the third whorl. Notice how the old shell, above the fracture (F) presents a pitted appearance, suggesting that the periostracum and outer aragonite layer is compromised, while the new shell, below the fracture, appears pristine.

Figure 9. Light microscope images of pristine specimens collected from the Greenland Sea ice margin after 4 day incubation. A, B and C were pristine, actively swimming specimens incubated at A. Ambient, B. $650 \mu$ atm target $p \mathrm{CO}_{2}$ and C. $800 \mu$ atm target $p \mathrm{CO}_{2}$. A remained fully translucent superficial scratch marks appear after living specimens with pristine shells incubated in undersaturated waters, B and C. Non-living specimens incubated in ambient waters, $\mathrm{D}$ and at $650 \mu \mathrm{atm}$ target $p \mathrm{CO}_{2}, \mathrm{E}$ both exhibited uniform dissolution across the entire shell, but the sheen of periostracum can still be seen externally, indicating that the shell is dissolving internally.

Figure 10. SEM images showing scratches indicative of failed predation attempts. Scratches were observed on J4, J5 and J6, from the Greenland Sea ice margin and also one specimen collected from the Greenland Sea open water site, D.

\section{Figure 11. Schematic showing possible history of damage and exposure to} undersaturated waters of the 2011 recruitment, collected on June $18^{\text {th }} 2012$ as juveniles. 
697 Table 1. Location and dates of sites discussed in this study.

$\begin{array}{llll}\text { Date Location Lat Long } & \text { Lat }\end{array}$

$18^{\text {th }}$ June $2012 \quad$ Greenland Sea ice margin (sea ice) $\quad 78.16 \quad-4.18$

$\begin{array}{llll}21^{\text {st }} \text { June } 2012 \quad \text { Greenland Sea (open water) } & 77.93\end{array}$

$\begin{array}{lll}23^{\text {rd }} \text { June } 2012 \quad \text { Barents Sea (open water) } & 74.09 & 26.00\end{array}$

698

699

700 Table 2. Incubation of pristine juvenile specimens collected within Greenland Sea ice.

\begin{tabular}{rrccccc}
\hline Target pCO2 & Salinity & TA & Temp & DIC & $p C O 2$ & $\Omega A r$ \\
\hline ambient & 32.59 & 2229.3 & $\mathbf{- 1 . 5 8}$ & 2120.9 & $\mathbf{3 4 4 . 7}$ & $\mathbf{1 . 3 2}$ \\
650 & 32.59 & 2241.8 & $\mathbf{- 1 . 5 8}$ & 2154.7 & $\mathbf{6 5 7 . 4}$ & $\mathbf{0 . 7 6}$ \\
800 & 32.59 & 2231.3 & $\mathbf{- 1 . 5 8}$ & 2198.1 & $\mathbf{8 1 0 . 3}$ & $\mathbf{0 . 6 3}$
\end{tabular}

701 
Click here to download high resolution image

Fig. 1.

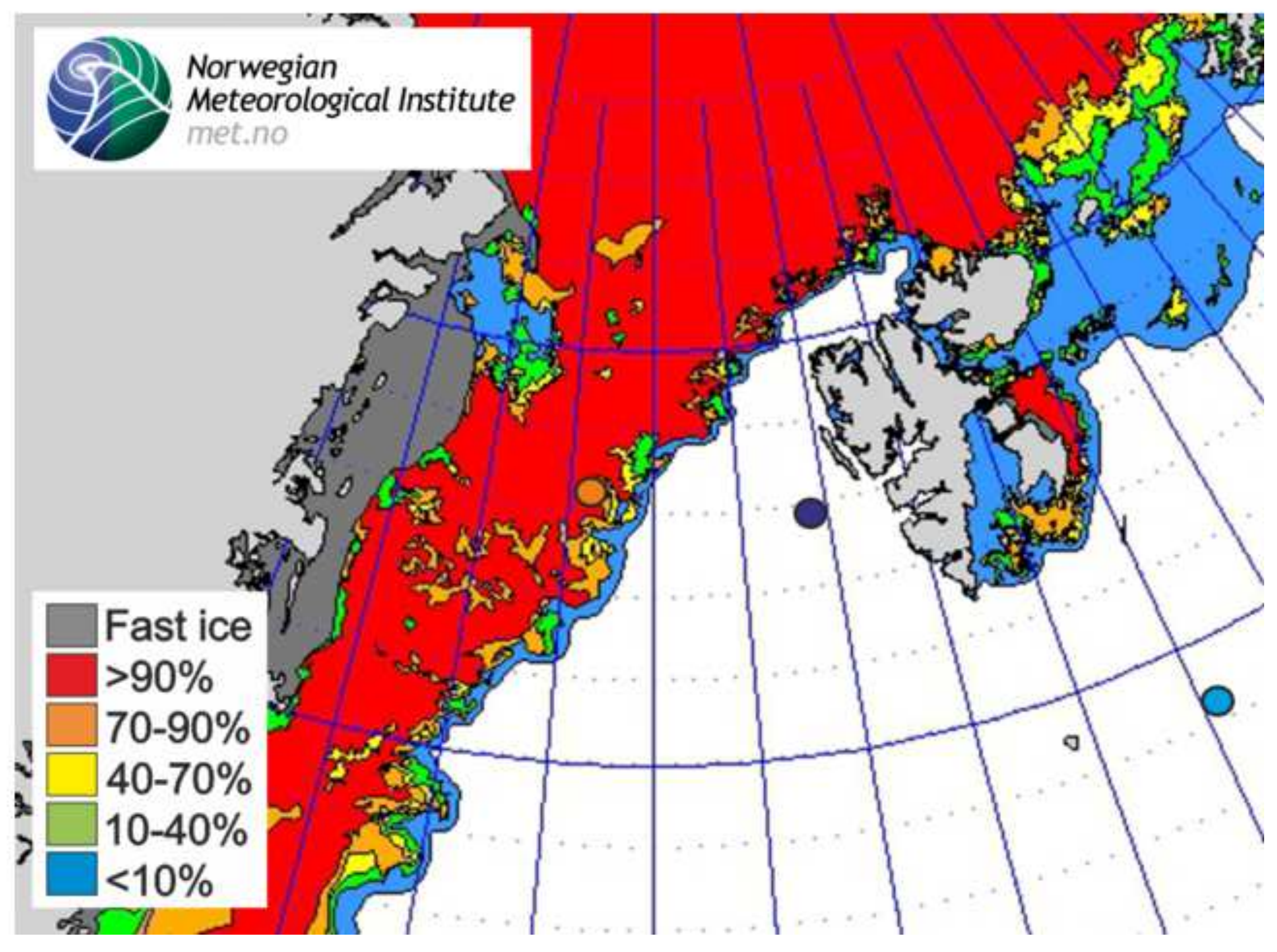

Meteorological Institute 
Click here to download high resolution image

Fig. 2

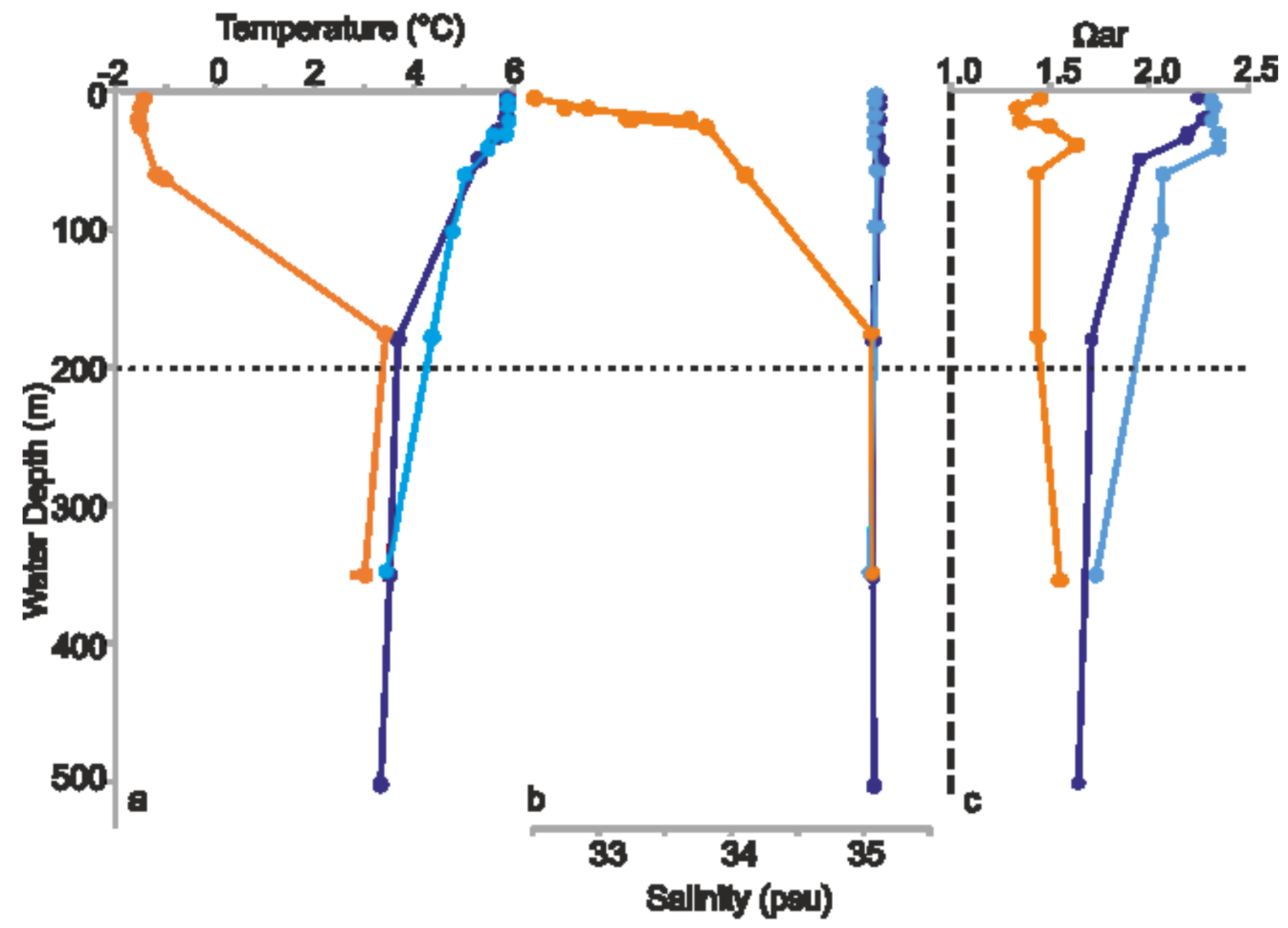




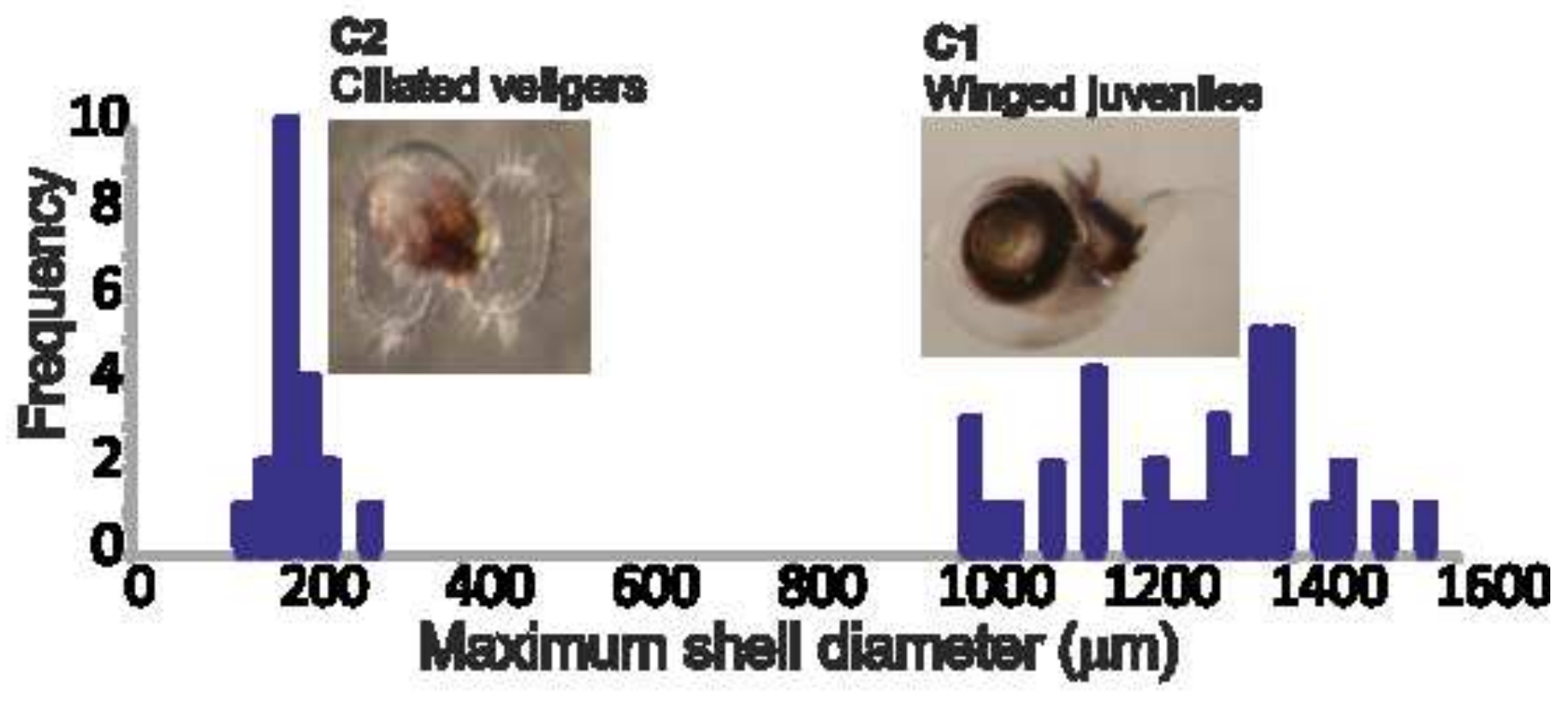


Click here to download high resolution image

Fig. 4

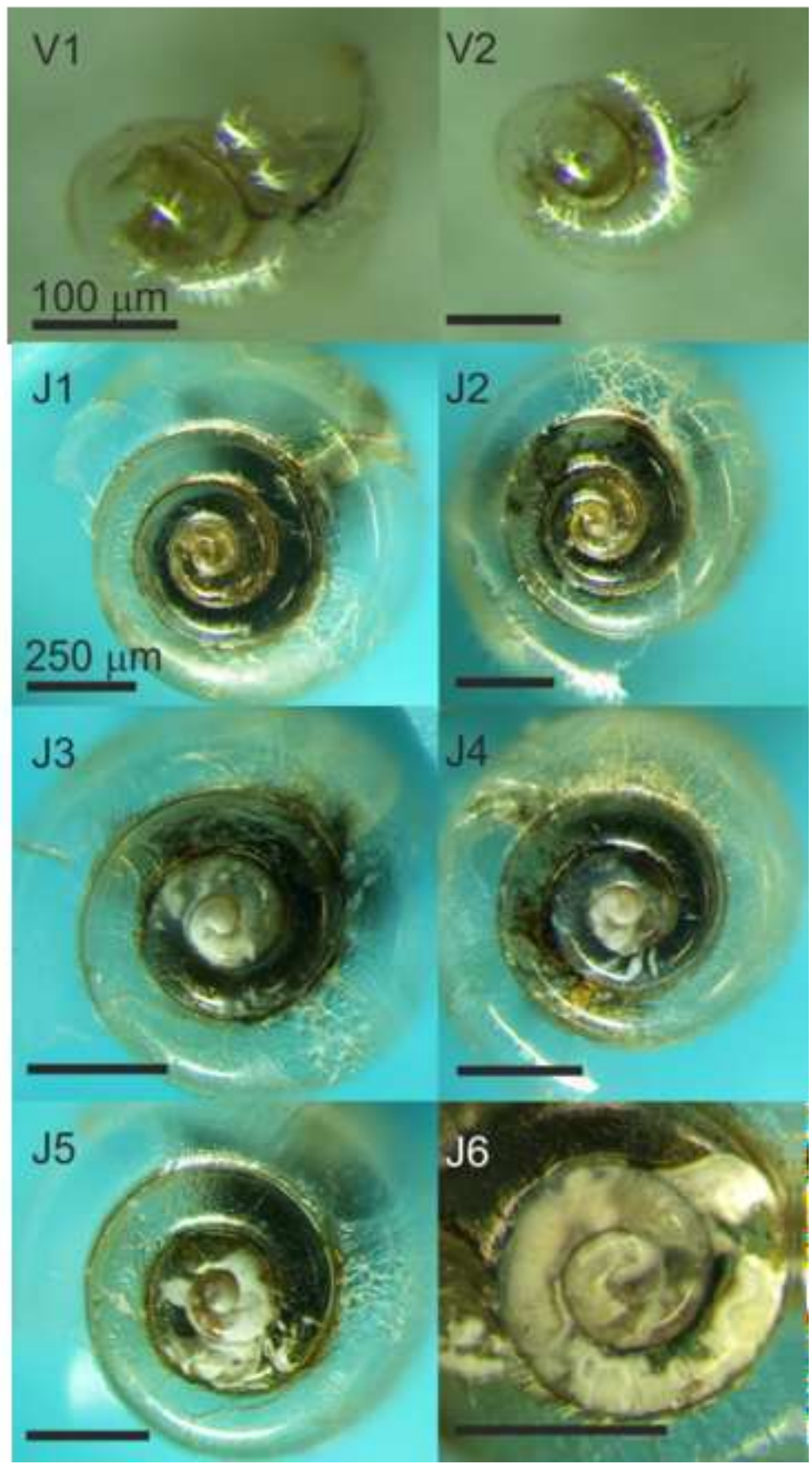




\section{Figure 5}

Click here to download high resolution image

\section{Fig. 5}

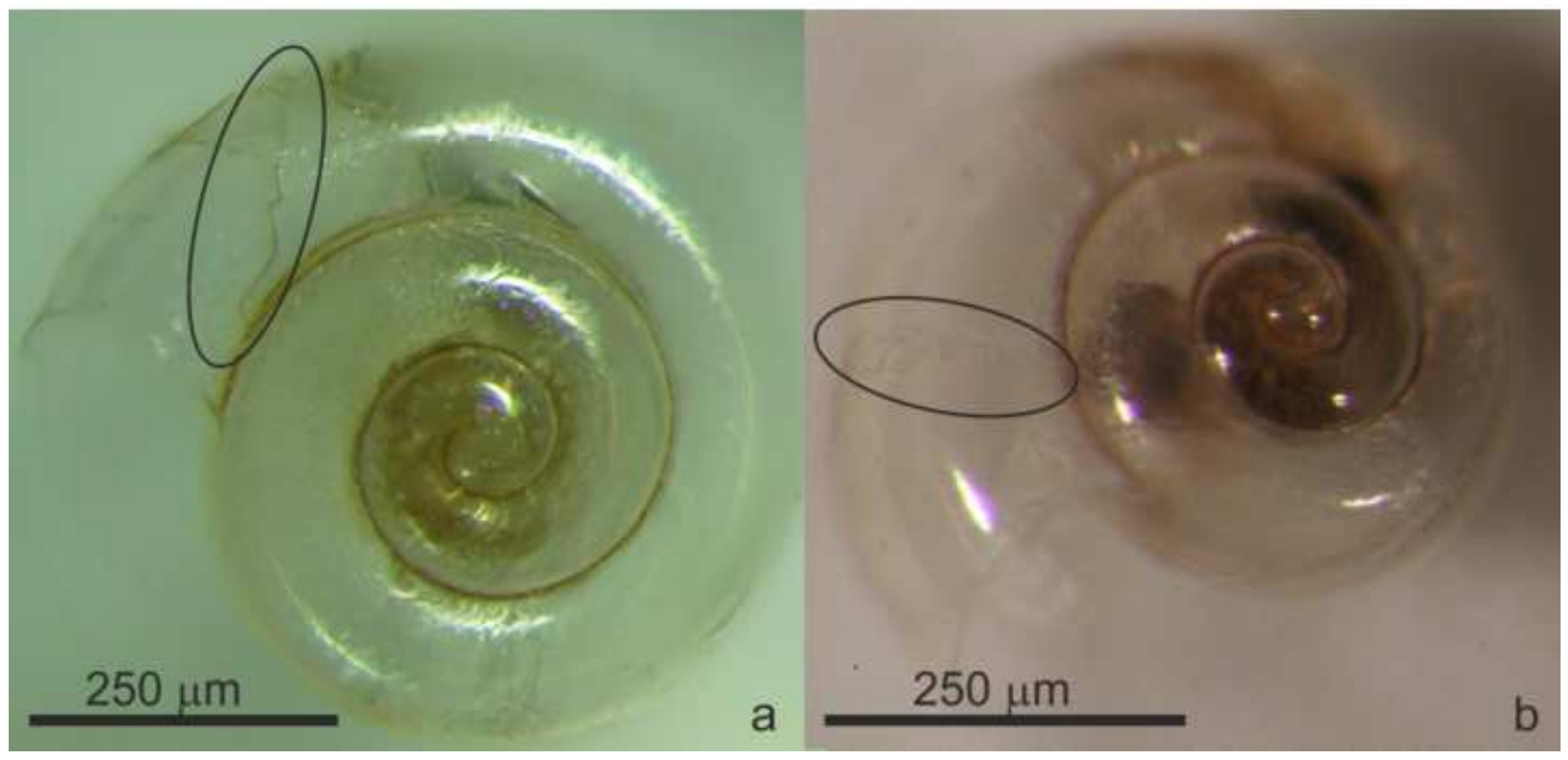


Click here to download high resolution image

Fig 6
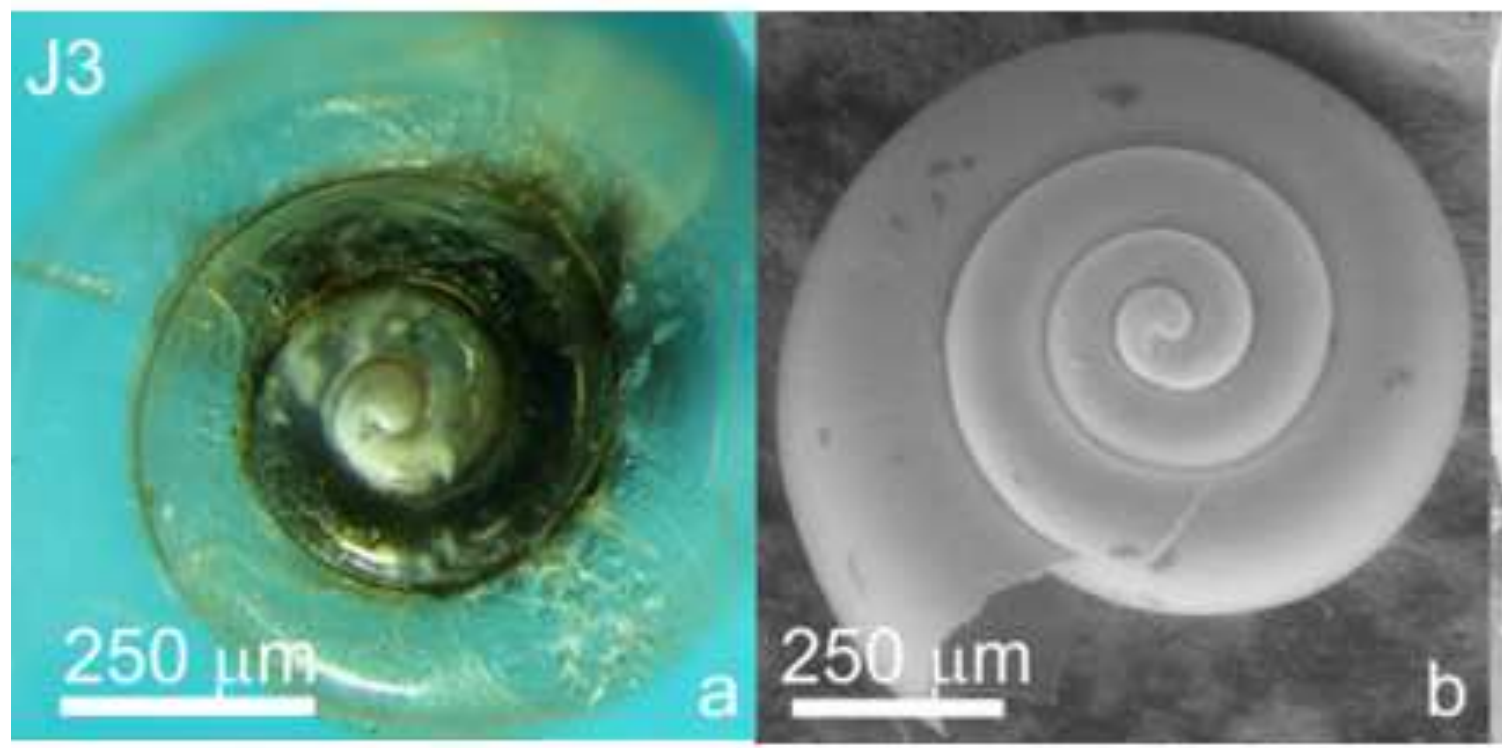

a

$250 \mathrm{im}$

b
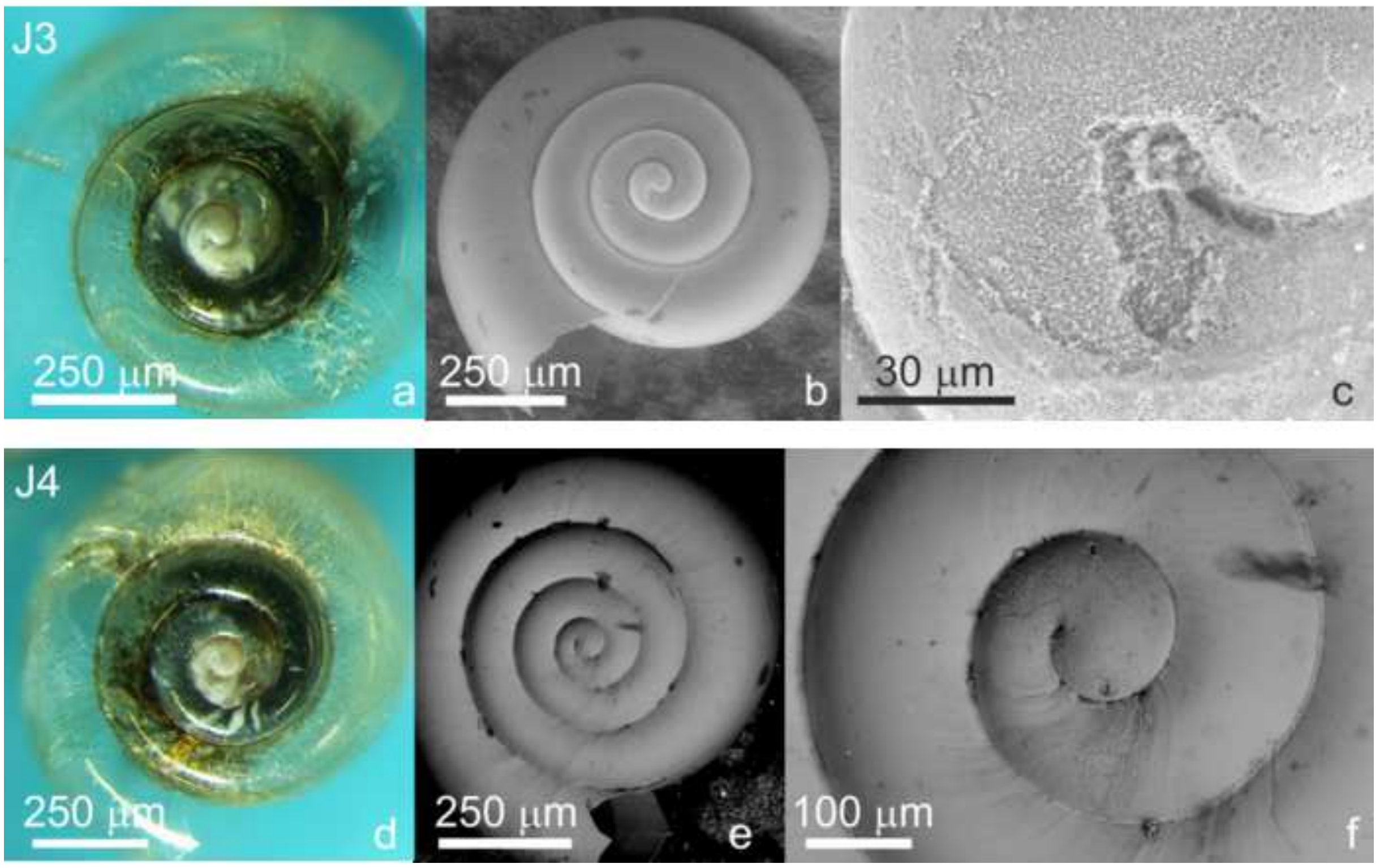
Click here to download high resolution image

\section{Fig 7}

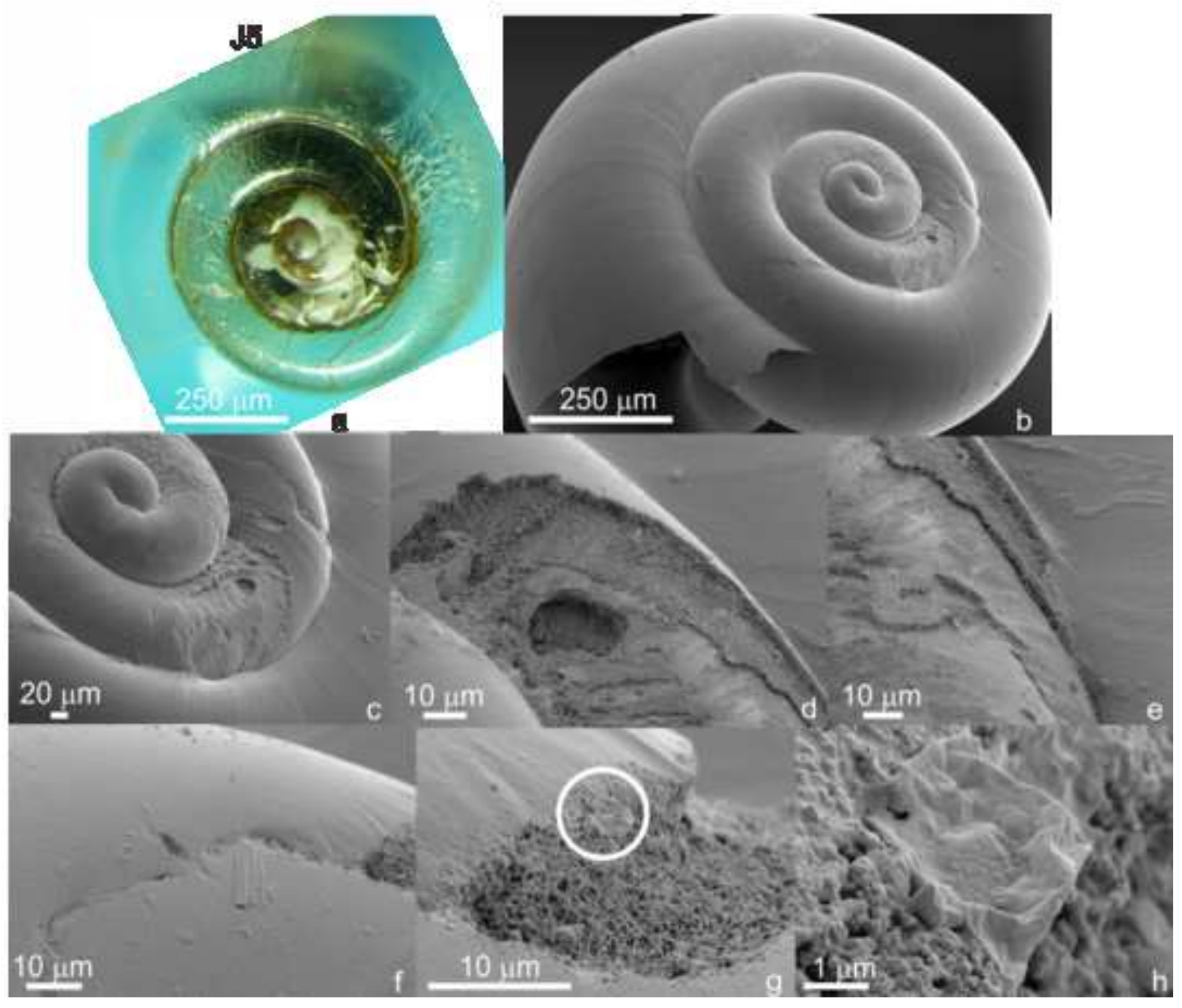


Figure 8
Click here to download high resolution image

\section{Fig 8}

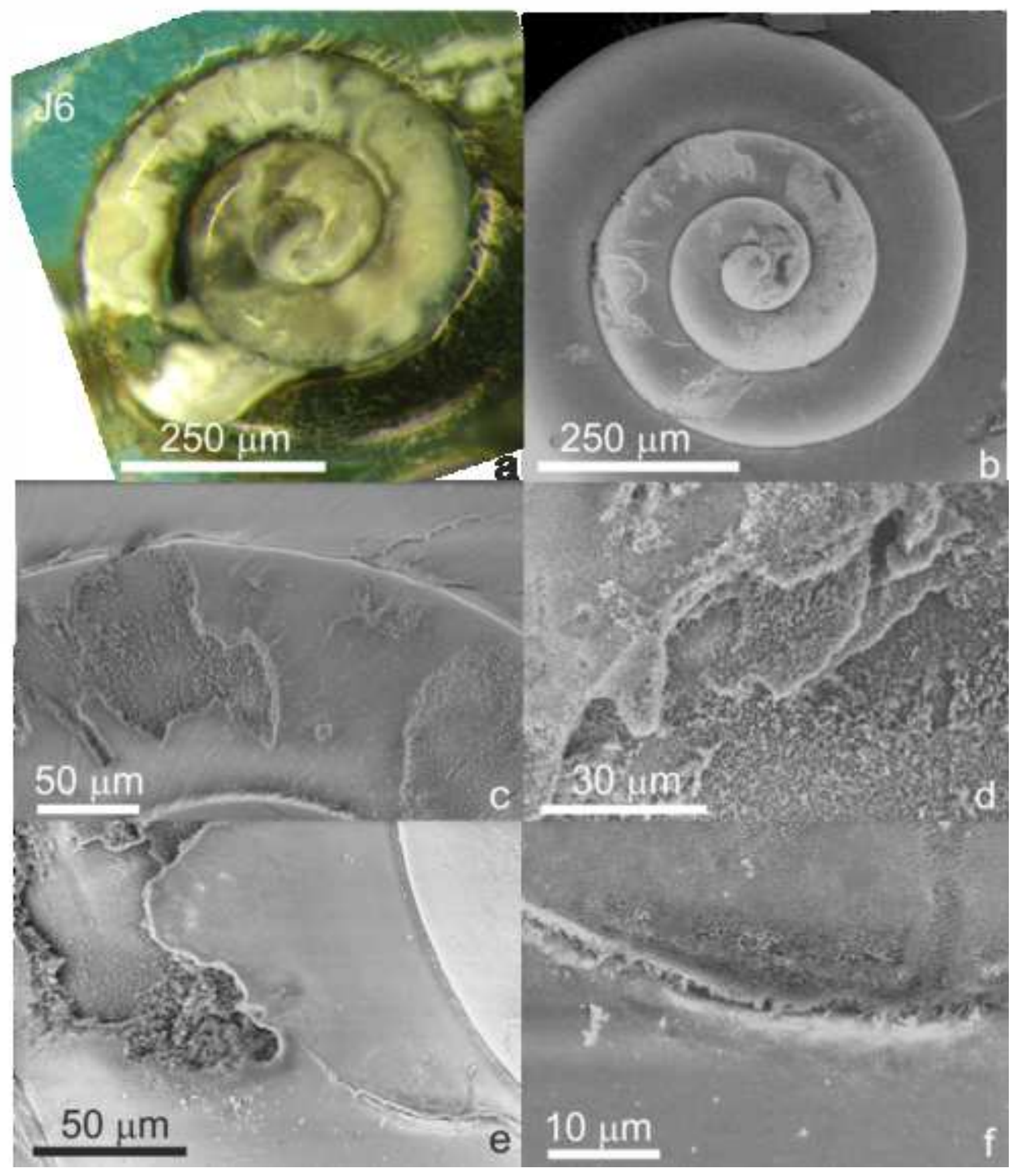




\section{Fig 9}

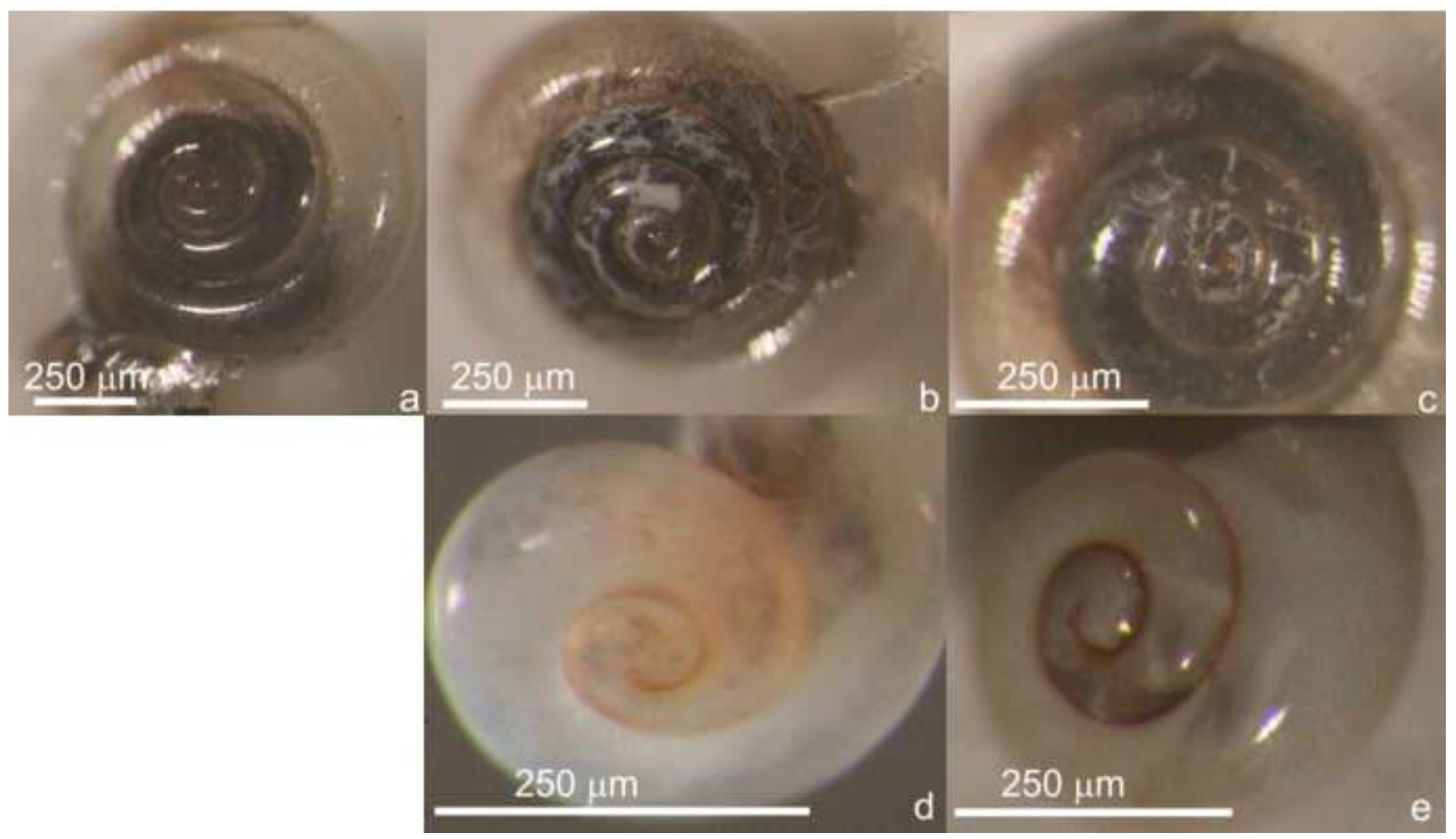


Click here to download high resolution image

\section{Fig 10}
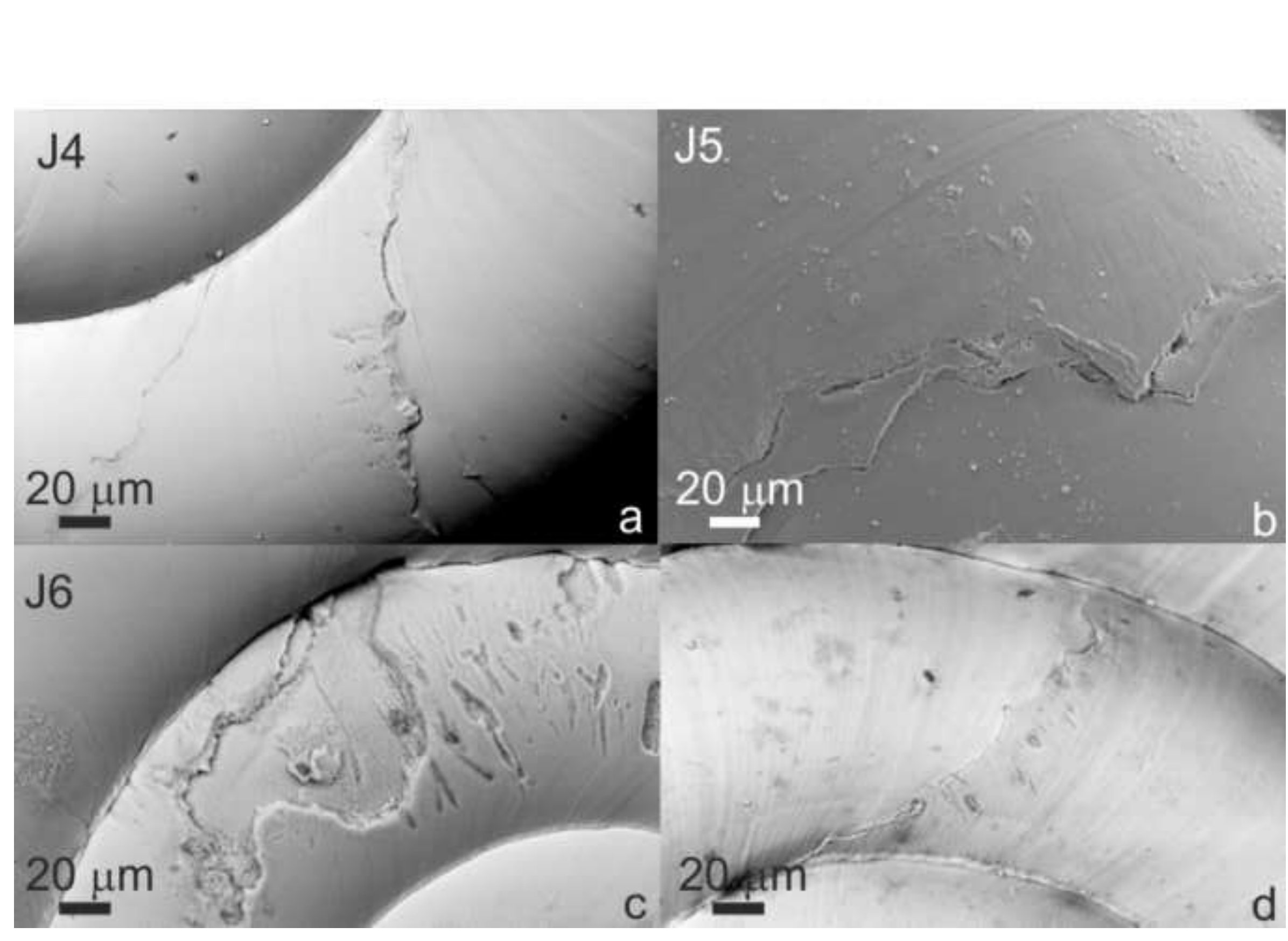

d 


\section{Fig 11}

\section{Summer 2011

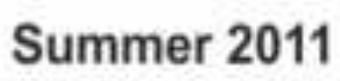

Sea ice begins to reform

\section{Winter 2011/2012}

\section{Summer 2012}
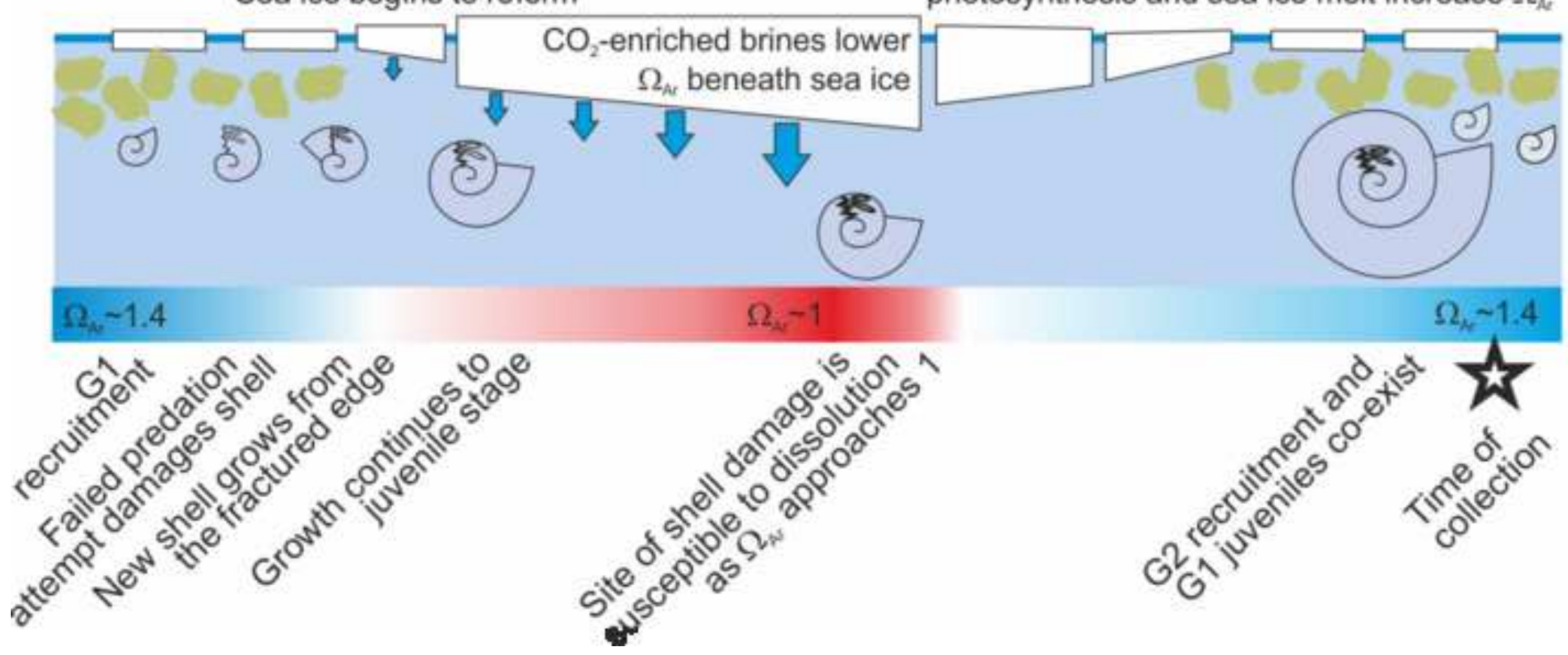
photosynthesis and sea ice melt increase $\Omega_{\text {A }}$ 